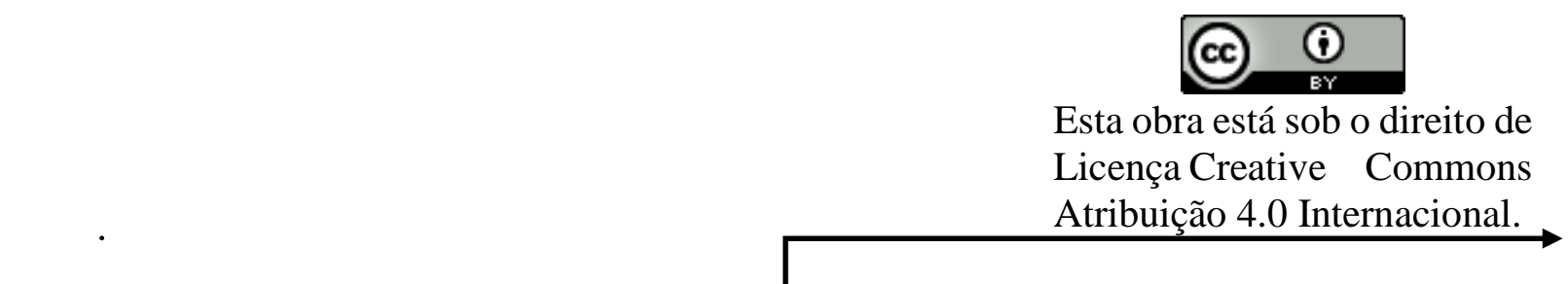

\title{
INCLUSÃO ESCOLAR: O SURDO E SUAS LIMITAÇÕES NO ENSINO FUNDAMENTAL
}

Léa Karla Carvalho Palmeira Barros ${ }^{1}$

Flávia Barboza Ferreira ${ }^{2}$

Francyne Pedrosa da Silva ${ }^{3}$

Rubiana de Gusmão Moreno da Rocha Omena ${ }^{4}$

\section{RESUMO}

O presente trabalho pretende refletir alguns aspectos relacionados à inclusão educacional, apresentando estudos publicados sobre o tema no período de 2015 a 2019 no ensino fundamental, e mostrar a forma pela qual esse assunto tem sido tratado no contexto social. Reúne no texto concepções de inclusão educacional, ensino regular, inclusão escolar, termos que se complementam, entendidos como um processo de reconhecimento do direito à escolarização das pessoas portadoras de deficiência auditiva, preferencialmente no ensino regular. Tem por objetivo analisar publicações acerca da importância da inclusão educacional no processo de ensino aprendizagem do surdo, através do método de revisão bibliográfica exploratória-descritiva, de caráter quanti/qualitativo, coletando bibliografias publicadas sobre o tema do estudo proposto. O estudo mostra pontos importantes da legislação sem abrir mão da constante melhoria da acessibilidade.

Palavras-chave: Inclusão educativa. Surdo. Ensino fundamental. Professor.

Submetido em março de 2020 e aceito em maio de 2020.

\footnotetext{
${ }^{1}$ Especialista em Psicopedagogia, graduação em Pedagogia pelo Centro Universitário CESMAC (2004).

${ }^{2}$ Especialista em Neuropsicologia, Língua Portuguesa e Literatura. Licenciada em Pedagogia. flaviaferreirababoz@gmail.com.

${ }^{3}$ Especialista em Organização do Trabalho Pedagógico: Orientação Educacional, Supervisão e Gestão Escolar. Licenciada em Pedagogia. francynepedrosa@outlook.com.

${ }^{4}$ Especialista em Psicopedagogia. Licenciada em Pedagogia. rubianaomena@hotmail.com.
} 


\section{INTRODUÇÃO}

Quem tem filho especial sabe: é um desafio encontrar escolas na rede regular de ensino, capacitadas e habilitadas para receber alunos com necessidades especiais. É importante ressaltar que antes de se praticar a inclusão, necessariamente se praticou a exclusão. Dessa forma, tão importante quanto praticarmos efetivamente a inclusão, é deixarmos de praticar a exclusão.

Como a maioria das escolas não estão fisicamente adaptadas, por exemplo, para receber uma cadeira de rodas seja pela falta de rampas de acesso, seja pela falta de elevador, seja pela falta de banheiros adaptados, necessariamente está se praticando sim a exclusão, pois o aluno com deficiência não tem como acessar e se movimentar dentro do ambiente escolar. Este é um exemplo de uma pessoa cadeirante é tão "clássico" quanto o para o público surdo que será o alvo deste trabalho. Como é que um aluno surdo pode desenvolver capacidades físicas, intelectuais e até mesmo emocionais sem poder interagir com os colegas de sala e, principalmente, os professores?

Precisamos entender que estamos no mundo diversos, onde temos pessoas com necessidades diversas, entre eles pessoas com necessidades especiais, que precisam ter a capacidade de acessar a escola. Antes de adentrar o assunto da educação inclusiva, ou seja, a educação dentro da sala de aula, é necessário ampliar o olhar e enxergar os alunos e alunas com necessidades especiais, e garantir que eles consigam chegar à sala de aula.

Uma vez que o aluno consiga acessar a sala de aula, o meio que ele vai estudar, deparamo-nos com uma outra questão: reclamação com relação à falta de capacitação dos professores e do quadro dos funcionários em geral de lidar com esses alunos. Alguns podem perguntar: mas não existem instituições preparadas para receber pessoas surdas ou que tenha outra necessidade especial? Pois bem, dessa maneira entramos numa outra questão: o Plano Nacional de Ensino, também conhecido como PNE, que traz na meta 4 a universalização para estudantes com algum tipo de deficiência ou transtorno, e que as escolas garantam um sistema educacional inclusivo e especializado.

Em escolas que praticam efetivamente com a inclusão escolar, vê-se um trabalho em conjunto entre aluno, a família do aluno, os professores, os diretores e outros profissionais, todos participando para que se possa criar um plano de educação para a criança. É possível praticar a inclusão escolar de forma efetiva com resultados satisfatórios. 
A integração escolar estimula o desenvolvimento das crianças de forma geral e não é diferente junto às crianças com necessidades especiais, atua como função inclusora e terapeuta, além de estimular conivência com a diferença não apenas para as crianças com necessidades especiais, mas, também, para os demais que convivem com essa criança porque atualmente temos um debate amplo na sociedade relativo à inclusão, relativo à diversidade. A realidade é que uma pessoa que é diferente, por ter necessidades especiais, igualmente tem todo o direito de conviver em qualquer ambiente que queira, assim como como qualquer outra.

Este trabalho tem por objetivo analisar publicações acerca da inclusão educacional no processo de ensino

\section{METODOLOGIA}

Esta pesquisa é uma revisão bibliográfica exploratória-descritiva, de caráter quanti/qualitativo e que consiste em buscar bibliografias publicadas sobre o tema do estudo proposto, tendo a finalidade de colocar o pesquisador em contato direto com tudo o que foi escrito sobre determinado assunto (MARCONI E LAKATOS, 2010; RODRIGUES, 2011). A pesquisa bibliográfica faz uso da leitura, da seleção e do fichamento para interesse do desenvolvimento da pesquisa em pauta, aprendizagem do surdo nos períodos de 2015 a 2019 no Brasil. Os objetivos específicos são: Identificar concepções da inclusão educacional; identificar as dificuldades encontradas pelos professores da escola em relação ao processo de alfabetização e inclusão desenvolvido com seus alunos surdos; mostrar os direitos à inclusão educacional por parte de alunos com necessidades especiais.

A princípio, trataremos sobre a Educação Inclusiva e o Plano Nacional de Educação; em seguida, os tópicos: Inclusão Educacional e Deficiência Auditiva e Quem é o surdo? Por fim, a descrição do percurso metodológico, a apresentação dos resultados e discussão, as considerações finais e as referências.

buscando conhecer e coletar contribuições científicas acerca do assunto falado.

A vivência como coordenadora pedagógica da Escola Cecília Meireles, em Maceió, impulsionou a pesquisar sobre a importância da Inclusão Educacional no ensino fundamental, com ênfase no público surdo. Efetuamos uma investigação das publicações acadêmicas online que tenham por temática abordada a educação inclusiva do surdo no ensino fundamental. Em seguida, elaboramos uma tabela com os trabalhos selecionados, com: Categoria, Título, Nome, Ano e Periódico do material 
no período de tempo de cinco anos, 2015 a 2019, no Brasil e em diferentes áreas da ciência.

A princípio, os artigos foram pesquisados em plataformas online captados de periódicos indexados de cunho acadêmico, de modo particular, utilizamos o Google Acadêmico, as publicações do site Scielo e a base de dados da Biblioteca Digital Brasileira de Teses e Dissertações (BDTD).
Em seguida, foram escolhidos os que correspondiam aos anos 2015, 2016, 2017, 2018 e 2019. Muitos foram os materiais encontrados a respeito da morte e o processo de morrer; sobre a ciência da tanatologia, poucos foram achados. Nas referências consta o uso de quarenta e nove trabalhos para fundamentação teórica deste, divididos entre artigos, manual, capítulos de livros, monografias e teses.

Tabela 1 - Detalhamento das etapas da revisão bibliográfica.

\begin{tabular}{|c|c|c|}
\hline Etapa & Cada etapa & Detalhes \\
\hline \multirow[t]{6}{*}{$1^{\mathrm{a}}$} & Tema & Inclusão educacional: o surdo tem lugar no ensino fundamental? \\
\hline & Pergunta norteadora & $\begin{array}{l}\text { De acordo com as leis e a realidade vigente, o surdo tem lugar no } \\
\text { ensino fundamental? }\end{array}$ \\
\hline & Objetivo geral & $\begin{array}{l}\text { Analisar publicações acerca da importância da inclusão } \\
\text { educacional no processo de ensino aprendizagem do surdo. }\end{array}$ \\
\hline & Objetivos específicos & $\begin{array}{l}\text { Identificar concepções da inclusão educacional; } \\
\text { Identificar as dificuldades encontradas pelos professores da escola } \\
\text { em relação ao processo de alfabetização e inclusão desenvolvido } \\
\text { com seus alunos surdos; } \\
\text { Mostrar os direitos à inclusão educacional por parte de alunos com } \\
\text { necessidades especiais. }\end{array}$ \\
\hline & Descritores & $\begin{array}{l}\text { Inclusão educacional, Inclusão escolar, Deficiência auditiva, Plano } \\
\text { Nacional de Educação. }\end{array}$ \\
\hline & $\begin{array}{l}\text { Desenvolvimento teórico e } \\
\text { referências }\end{array}$ & $\begin{array}{l}\text { Google Acadêmico, site Slielo, base de dados da Biblioteca Digital } \\
\text { Brasileira de Teses e Dissertações (BDOT) e livro. }\end{array}$ \\
\hline \multirow[t]{3}{*}{$2^{\mathrm{a}}$} & Coleta de dados & Novembro e dezembro de 2019. \\
\hline & Critérios de inclusão & $\begin{array}{l}\text { Publicações entre } 2015 \text { e } 2019 \text {, contendo a expressão de busca no } \\
\text { "Título", "Assunto" e "Resumo", com acesso ao texto completo } \\
\text { sobre Inclusão Educacional e/ou Inclusão Escolar voltada ao } \\
\text { público surdo. }\end{array}$ \\
\hline & Critérios de exclusão & $\begin{array}{l}\text { Publicações que não contemplam a Inclusão Educacional, Inclusão } \\
\text { Escolar, Escola Regular para o surdo. }\end{array}$ \\
\hline \multirow[t]{3}{*}{$3^{\mathrm{a}}$} & $\begin{array}{l}\text { Número de publicações } \\
\text { encontradas }\end{array}$ & 61 \\
\hline & $\begin{array}{l}\text { Número de publicações } \\
\text { incorporadas }\end{array}$ & 34 \\
\hline & $\begin{array}{l}\text { Número de publicações } \\
\text { descartadas }\end{array}$ & 27 \\
\hline $4^{\mathrm{a}}$ & $\begin{array}{l}\text { Temáticas contribuintes } \\
\text { obtidas nas publicações }\end{array}$ & $\begin{array}{l}\text { Garantias do direito à inclusão educacional; } \\
\text { Reflexões a respeito da inclusão } \\
\text { Direitos instituídos no Plano Nacional de Educação; } \\
\text { Processo escolar do aluno incluso }\end{array}$ \\
\hline $5^{a}$ & Análise e produção do trabalho & Resultado e discussão \\
\hline $6^{a}$ & Publicação & Conclusão deste trabalho \\
\hline
\end{tabular}


Tabela 2 - Lista a categoria e os títulos dos artigos analisados, seus autores, o ano da publicação e o periódico em que foram publicados.

\begin{tabular}{|c|c|c|c|c|c|}
\hline Categoria & Título & Autor & Ano & Trabalho & Instituição \\
\hline \multirow[t]{11}{*}{ Educação } & $\begin{array}{l}\text { Rede de apoio à } \\
\text { escolarização inclusiva na } \\
\text { educação básica: dos } \\
\text { limites às possibilidades }\end{array}$ & Calheiros & 2019 & Tese & UFSCAR \\
\hline & $\begin{array}{l}\text { As concepções dos } \\
\text { professores a respeito da } \\
\text { inclusão dos alunos com } \\
\text { necessidades educacionais } \\
\text { especiais: uma discussão } \\
\text { em grupo }\end{array}$ & Caetano & 2019 & Dissertação & UNIPAMPA \\
\hline & $\begin{array}{lr}\text { Inclusão escolar } & \text { na } \\
\text { perspectiva docente: a } & \text { a } \\
\text { realidade do } & \text { Atendimento } \\
\text { Educacional Especializado } \\
\text { nas escolas públicas } \\
\text { municipais } & \text { de } \\
\text { Uruguaiana/RS } & \end{array}$ & Teixeira & 2019 & Dissertação & UNIPAMPA \\
\hline & $\begin{array}{l}\text { Formação continuada do } \\
\text { gestor escolar: instrumento } \\
\text { facilitador no processo de } \\
\text { inclusão de alunos com } \\
\text { deficiência nas escolas } \\
\text { estaduais de Uberaba }\end{array}$ & Marcelino & 2019 & Dissertação & UFJF \\
\hline & $\begin{array}{l}\text { Educação especial e } \\
\text { educação integral: um } \\
\text { estudo de caso sobre as } \\
\text { interfaces em uma escola } \\
\text { pública }\end{array}$ & Dill & 2019 & Dissertação & UFRGS \\
\hline & $\begin{array}{lrr}\text { Educação } & \text { especial } & \text { e } \\
\text { inclusão } & \text { escolar } & \text { na } \\
\text { educação } & \text { infantil } & \text { e } \\
\text { iniciais do } & \text { ensino } \\
\text { fundamental } & & \end{array}$ & Nascimento & 2019 & Dissertação & UFG \\
\hline & $\begin{array}{l}\text { Pedagogia na UFS: o lugar } \\
\text { da educação inclusiva } \\
\text { numa realidade excludente }\end{array}$ & Oliveira & 2019 & Dissertação & UFS \\
\hline & $\begin{array}{l}\text { Educação inclusiva em um } \\
\text { município do interior } \\
\text { goiano: análise de um } \\
\text { percurso }\end{array}$ & Miranda & 2019 & Dissertação & UFG \\
\hline & $\begin{array}{l}\text { Formação de professores } \\
\text { de matemática e o ensino } \\
\text { de matemática para } \\
\text { estudantes rardos: } \\
\text { reflexões acerca da } \\
\text { educação inclusiva }\end{array}$ & Silva & 2019 & Dissertação & UFPE \\
\hline & $\begin{array}{l}\text { Currículo e diferença na } \\
\text { educação especial em uma } \\
\text { perspectiva inclusiva }\end{array}$ & Pio & 2018 & Dissertação & UFG \\
\hline & $\begin{array}{l}\text { Contribuições do pacto } \\
\text { nacional pela alfabetização }\end{array}$ & Ávila & 2018 & Tese & UFSM \\
\hline
\end{tabular}




\begin{tabular}{|c|c|c|c|c|}
\hline $\begin{array}{l}\text { na idade certa na formação } \\
\text { de professores para atuar } \\
\text { na perspectiva inclusiva }\end{array}$ & & & & \\
\hline $\begin{array}{l}\text { Compondo sentidos sobre } \\
\text { a inclusão do aluno surdo: } \\
\text { as percepções dos sujeitos } \\
\text { envolvidos no proceso }\end{array}$ & Kikuichi & 2018 & Dissertação & UFTM \\
\hline $\begin{array}{l}\text { Gestão escolar e educação } \\
\text { inclusiva: articulação entre } \\
\text { o atendimento educacional } \\
\text { especializado e o ensino } \\
\text { regular }\end{array}$ & Flores & 2018 & Dissertação & UNESP \\
\hline $\begin{array}{l}\text { Práticas pedagógicas do } \\
\text { professor de história de } \\
\text { ensino médio em turma } \\
\text { regular com a presença de } \\
\text { aluno surdo }\end{array}$ & Perales & 2018 & Dissertação & UFG \\
\hline $\begin{array}{l}\text { A cultura da escola } \\
\text { inclusiva na perspectiva } \\
\text { dos alunos surdos }\end{array}$ & Morás & 2018 & Dissertação & UNIOESTE \\
\hline $\begin{array}{l}\text { Tenho um aluno surdo: } \\
\text { aprendi o que fazer! }\end{array}$ & Machado & 2017 & Dissertação & UNB \\
\hline $\begin{array}{l}\text { Educação de surdos: } \\
\text { estudo bibliométrico de } \\
\text { teses e dissertações (2010- } \\
\text { 2014) }\end{array}$ & Ramos & 2017 & Tese & UFSCAR \\
\hline $\begin{array}{l}\text { O processo de } \\
\text { alfabetização de surdos nos } \\
\text { anos iniciais do ensino } \\
\text { fundamental: uma análise } \\
\text { sob a perspectiva de } \\
\text { professores }\end{array}$ & Bomfim & 2017 & Dissertação & UFVJM \\
\hline $\begin{array}{l}\text { A inclusão educacional do } \\
\text { sujeito surdo: direito } \\
\text { garantido ou reprimido? }\end{array}$ & Ruzza & 2016 & Dissertação & PUC-SP \\
\hline $\begin{array}{l}\text { Interações da criança surda } \\
\text { em escola comum }\end{array}$ & Franzoi & 2016 & Dissertação & UCS \\
\hline $\begin{array}{l}\text { A interação social dentro } \\
\text { de uma escola com } \\
\text { perspectivas inclusivas: } \\
\text { análise do ensino de } \\
\text { Ciências para alunos } \\
\text { surdos }\end{array}$ & Hencklein & 2016 & Tese & UNESP \\
\hline $\begin{array}{l}\text { A inclusão e escolarização } \\
\text { dos alunos com deficiência } \\
\text { auditiva e surdez no ensino } \\
\text { fundamental em } \\
\text { Brasilândia/MS: desafios, } \\
\text { avanços e perspectivas }\end{array}$ & Jesus & 2016 & Dissertação & UEMS \\
\hline $\begin{array}{l}\text { Práticas pedagógicas em } \\
\text { sala de aula com surdos: } \\
\text { implicações nos processos } \\
\text { de ensino e de } \\
\text { aprendizagem }\end{array}$ & Ziesmann & 2015 & Dissertação & UNIJUÍ \\
\hline
\end{tabular}




\begin{tabular}{|c|c|c|c|c|c|}
\hline & $\begin{array}{l}\text { Investigação matemática } \\
\text { em sala de aula: uma } \\
\text { proposta para a inclusão do } \\
\text { aluno surdo no ensino } \\
\text { regular }\end{array}$ & Santos & 2015 & Dissertação & IFG \\
\hline & $\begin{array}{l}\text { Inclusão: uma mudança no } \\
\text { olhar da comunidade } \\
\text { escolar para a construção } \\
\text { de uma escola melhor } \\
\text { inclusiva. }\end{array}$ & Papa et al & 2015 & Artigo & PUC-SP \\
\hline & $\begin{array}{llr}\text { As dificuldades } & \text { no } \\
\text { processo de } & \text { inclusão } \\
\text { educacional } & \text { no } & \text { ensino } \\
\text { regular: a visão dos } \\
\text { professores } & \text { do ensino } \\
\text { fundamental } & & \end{array}$ & Konkel et al & 2015 & Artigo & PUC-PR \\
\hline \multirow[t]{3}{*}{$\begin{array}{l}\text { Ciências } \\
\text { Humanas e } \\
\text { Sociais }\end{array}$} & $\begin{array}{l}\text { Políticas para Educação } \\
\text { Inclusiva no Município de } \\
\text { Campinas: o que dizem as } \\
\text { legislações nacionais e } \\
\text { municipais. }\end{array}$ & Lourenço & 2019 & Dissertação & UNESP \\
\hline & $\begin{array}{l}\text { O surdo na perspectiva } \\
\text { inclusiva: } \\
\text { permanência e êcesso, } \\
\text { ensino (?) }\end{array}$ & Reis & 2019 & Tese & UNESP \\
\hline & $\begin{array}{l}\text { A inclusão de crianças com } \\
\text { deficiência na educação } \\
\text { infantil: políticas públicas } \\
\text { na visão dos professores }\end{array}$ & Martins & 2018 & Dissertação & UNESP \\
\hline Filosofia & $\begin{array}{lrr}\text { Biopolítica e } & \text { educação: } \\
\text { desafios da } & \text { inclusão } \\
\text { escolar das pessoas } & \text { com } \\
\text { deficiência } & & \text { no } \\
\text { neoliberalismo } & & \\
\end{array}$ & Matos & 2019 & Dissertação & UNESP \\
\hline \multirow[t]{2}{*}{ Letras } & $\begin{array}{l}\text { Práticas pedagógicas na } \\
\text { educação de surdos: } \\
\text { análise crítica do discurso } \\
\text { de professores da educação } \\
\text { básica }\end{array}$ & Silva & 2017 & Dissertação & UFS \\
\hline & $\begin{array}{lll}\text { Surdez, linguagem } & \mathrm{e} \\
\text { educação: quem ouve } & \\
\text { sujeito surdo? } & & \\
\text { sujem }\end{array}$ & Siqueira & 2015 & Dissertação & UFAM \\
\hline História & $\begin{array}{l}\text { Ensino de História para } \\
\text { alunos surdos em classes } \\
\text { inclusivas: práticas e } \\
\text { propostas }\end{array}$ & Santos & 2018 & Dissertação & UFRJ \\
\hline Linguística & $\begin{array}{l}\text { O letramento do aluno } \\
\text { surdo na escola regular: } \\
\text { perspectivas e desafios }\end{array}$ & Sena & 2017 & Dissertação & UFPB \\
\hline
\end{tabular}

Fonte: autoria própria. 


\section{RESULTADOS E DISCUSSÕES}

Realizamos uma pesquisa para encontrar artigos com as seguintes temáticas: escola inclusiva e inclusão escolar, ambas voltadas ao público surdo. Foram encontradas mais de 100 publicações, a maioria no modelo de dissertação e tese. Os resumos e as palavraschave de todos foram lidos para critério de seleção. Dessas mais de 100 publicações encontradas, 34 correspondiam ao padrão desta pesquisa, sendo colocadas na tabela acima. Os demais artigos foram descartados porque não satisfaziam os descritores desejados para a pesquisa.

Das 34 publicações selecionadas sobre inclusão educacional e/ou inclusão escolar que tocasse na questão do público surdo são: 5 teses de doutorado, 27 dissertações de mestrado e 2 artigos.

Figura 1 - Quantidade das publicações coletadas.

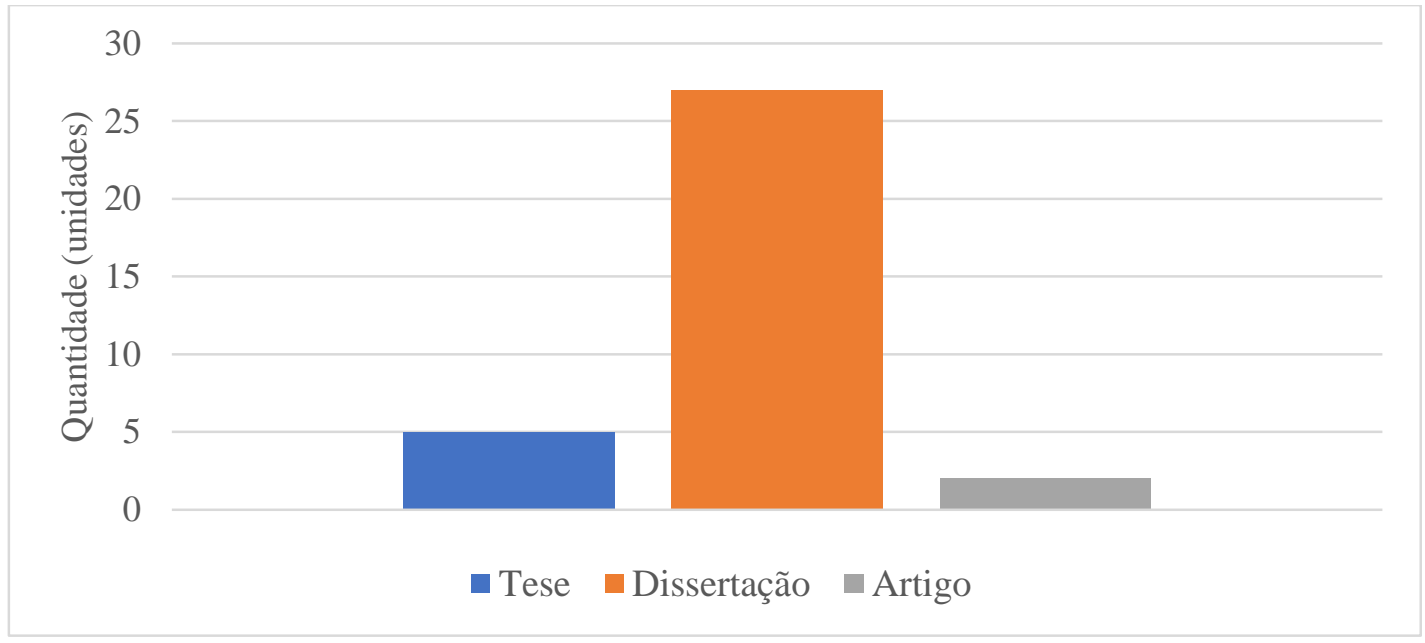

Fonte: autoria própria.

Observamos, na Figura 2, um alto índice de publicações no modelo de dissertações de mestrado acadêmico. Em contrapartida, quanto às teses de doutorado, verificamos um pequeno acréscimo, contudo, menor ainda foram as publicações de artigos encontradas.

Figura 2 - Quantidade de publicações por ano 


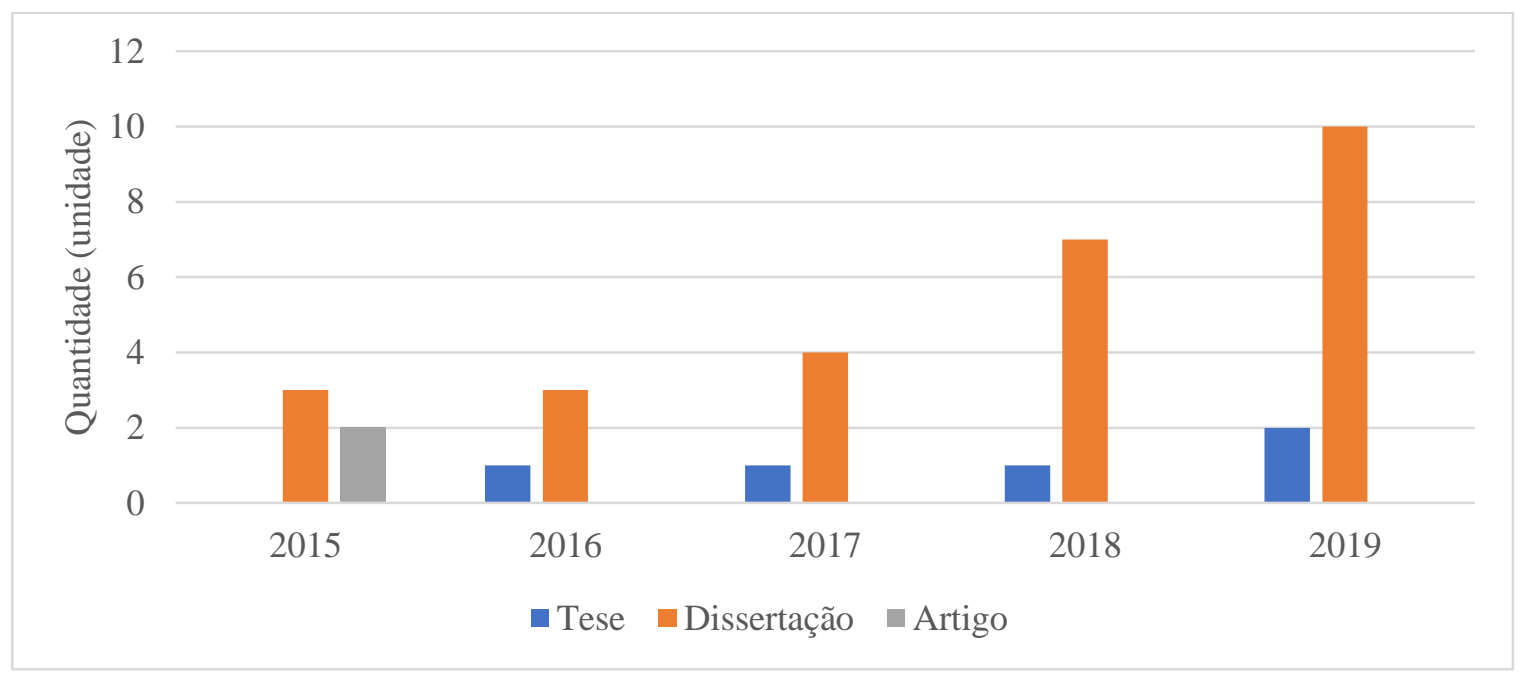

Fonte: autoria própria.

Organizando na ordem crescente, observamos que em 2015 o número de artigos publicados aparece, foram 2, porém, dissertações de mestrado foram publicadas 3; nenhuma tese de doutorado foi encontrada. Em 2016, uma tese de doutorado foi encontrada e 3 dissertações de mestrado. Em 2017 o número de tese de doutorado publicada continua com o mesmo número do ano anterior, mas a quantidade de dissertações de mestrado alcança mais um número e sobe para 4 . Em 2018 a publicação de tese de doutorado é de uma, em três anos seguidas, entretanto, o número de dissertações de mestrado continua subindo, dessa vez com o número de 7 publicações. Em 2019, 2 teses de doutorado são publicadas e as dissertações de mestrado aumentam ainda mais, sobe para 10. De 2016 a 2019, não encontramos nenhum artigo que se enquadrasse como requisito temático para este trabalho.

$\mathrm{Na}$ pesquisa, atentamos também às categorias das publicações inclusas na Tabela 1. Desse modo, encontramos nas publicações selecionadas as seguintes áreas: Educação, Ciências Humanas e Sociais (CHS), Filosofia, Letras, História e Linguística.

Figura 3 - Quantidade de publicações de acordo com as categorias científicas. 


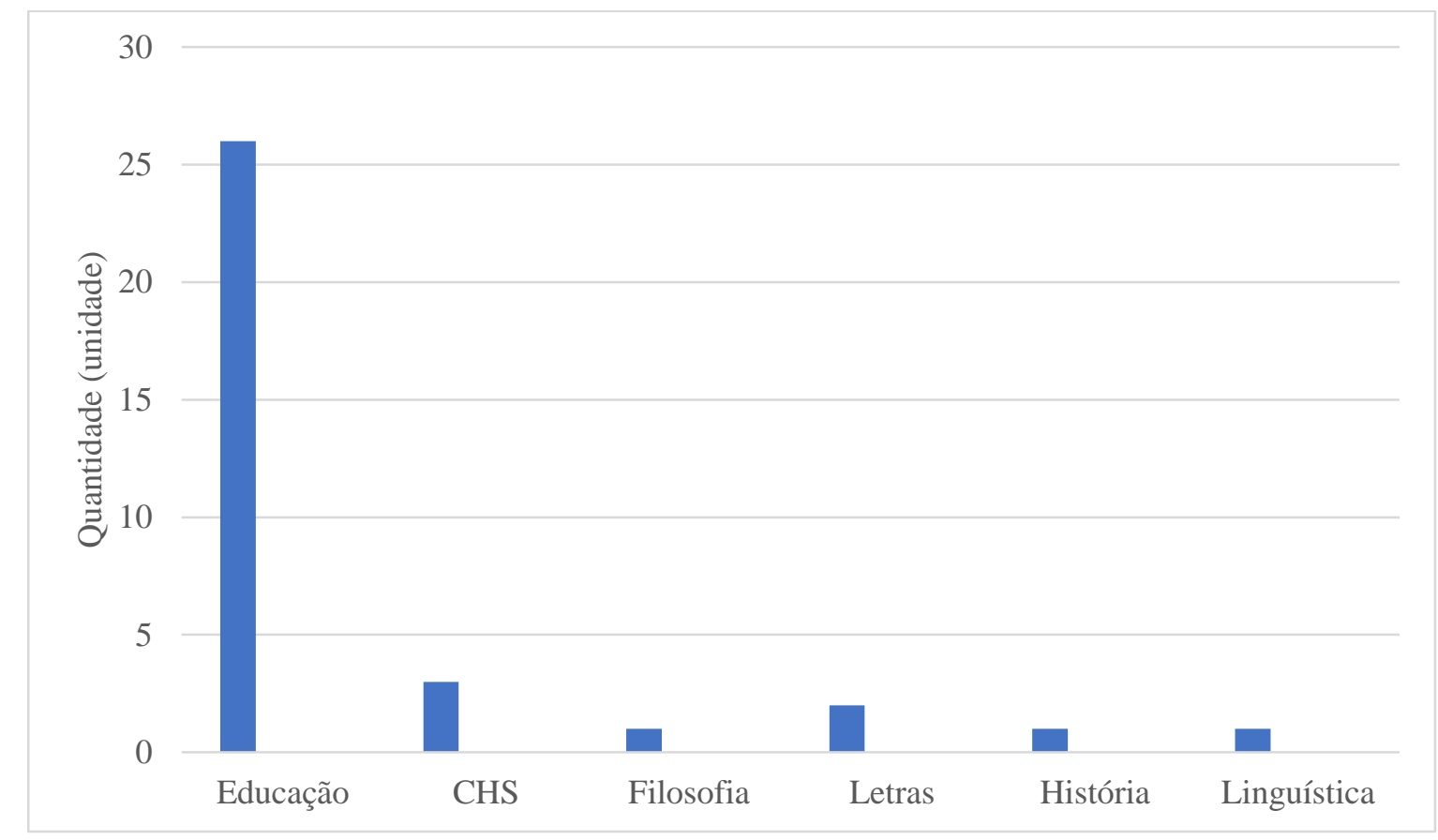

Fonte: autoria própria.

A Figura 3, acima, mostra o recorde da Educação em publicações acadêmicas acerca da temática da inclusão de alunos na educação, contando com alunos surdos, que mais publicou nesses últimos 5 anos, entre teses de doutorado, dissertações de mestrado e artigos. A saber: foram 26 publicações da categoria Educação; 3 da área das Ciências Humanas e Sociais; 1 da área da Filosofia; 2 da área de Letras; 1 da área da História; e 1 publicação da área da Linguística. Não incluímos na pesquisa artigos da literatura internacional porque nos propomos apenas coletar e analisar os estudos publicados no Brasil.

Com isso, mostramos que existem cada vez mais pesquisas e publicações pautadas na realidade da educação inclusiva. Uma vantagem que pode ajudar na formação dos profissionais em como saber lidar com alunos especiais, não especiais, pais e até outros profissionais, formando assim uma rede de apoio educacional para todos que contribuem para o desenvolvimento integral da escola.

\section{Educação inclusiva e o plano nacional de educação}

É uma modalidade de educação existente que introduz alunos com deficiência ou transtorno, ou com elevadas habilidades em escolas de ensino regular. A diversidade sugerida pela escola inclusiva é de participação para todos. Embora a modelo não esteja presente na maior parte das escolas, as que possuem apresentam resultados positivos: de um lado estão os alunos com deficiência, que usufruem de uma escola preparada para ajudá-los com o 
aprendizado; do outro, os demais alunos que aprendem a conviver com as diferenças de forma natural, a desenvolver o sentido de entreajuda e o respeito.

Antes do ano de 2003, o sistema educativo brasileiro seguia duas vertentes: a Escola Especial e a Escola Regular. A primeira, era para alunos com deficiências ou transtornos cognitivos-emocionais, ou, ainda, com altas habilidades; a segunda era o oposto, nenhum dos seus alunos tinha algum tipo de deficiência, transtorno ou altas habilidades. A educação inclusiva no Brasil foi uma implementação do Ministério da Educação e da Cultura (MEC) em 2003.

O Plano Nacional de Educação (PNE) atual integra os alunos que antes iriam para a escola especial à escola regular, eliminando barreiras nas escolas e construindo o acesso de pessoas com deficiência no ensino regular, congregando o segregado:

\begin{abstract}
"A inclusão propõe a desigualdade de tratamento como forma de restituir uma igualdade que foi rompida por formas segregadoras de ensino especial e regular. A escola justa e desejável para todos não se sustenta unicamente no fato de os homens serem iguais e nascerem iguais". (MONTOAN, 2006, p. 16).
\end{abstract}

A Lei $\mathrm{N}^{\circ} 13.005 / 2014$ aprovada, no PNE, é composta por vinte Metas, cada uma possuindo estratégias. De forma direta sobre a rede regular de ensino, expõe a Meta
4 (PNE, 2014): Universalizar, para a população de 4 (quatro) a 17 (dezessete) anos com deficiência, transtornos globais do desenvolvimento e altas habilidades ou superdotação, o acesso à educação básica e ao atendimento educacional especializado, preferencialmente na rede regular de ensino, com a garantia de sistema educacional inclusivo, de salas de recursos multifuncionais, classes, escolas ou serviços especializados, públicos ou conveniados.

Estratégias (transcritas):

“4.1) contabilizar, para fins do repasse
do Fundo de Manutenção e
Desenvolvimento da Educação Básica
e de Valorização dos Profissionais da
Educação - FUNDEB, as matrículas
dos (as) estudantes da educação
regular da rede pública que recebam
atendimento educacional
especializado complementar e
suplementar, sem prejuízo do
cômputo dessas matrículas na
educação básica regular, e as
matrículas efetivadas, conforme o
censo escolar mais atualizado, na
educação especial oferecida em
instituições comunitárias,
confessionais ou filantrópicas sem
fins lucrativos, conveniadas com o
poder público e com atuação exclusiva
na modalidade, nos termos da Lei no
11.494 , de 20 de junho de $2007 ;$

4.2) promover, no prazo de vigência deste PNE, a universalização do atendimento escolar à demanda manifesta pelas famílias de crianças de 0 (zero) a 3 (três) anos com deficiência, transtornos globais do desenvolvimento e altas habilidades ou superdotação, observado o que dispõe a Lei no 9.394, de 20 de dezembro de 1996, que estabelece as diretrizes e bases da educação nacional;

4.3) implantar, ao longo deste PNE, salas de recursos multifuncionais $\mathrm{e}$ 
fomentar a formação continuada de professores e professoras para o atendimento educacional especializado nas escolas urbanas, do campo, indígenas e de comunidades quilombolas;

4.4) garantir atendimento educacional especializado em salas de recursos multifuncionais, classes, escolas ou serviços especializados, públicos ou conveniados, nas formas complementar e suplementar, a todos (as) alunos (as) com deficiência, transtornos globais do desenvolvimento e altas habilidades ou superdotação, matriculados na rede pública de educação básica, conforme necessidade identificada por meio de avaliação, ouvidos a família e o aluno;

4.5) estimular a criação de centros multidisciplinares de apoio, pesquisa e assessoria, articulados com instituições acadêmicas e integrados por profissionais das áreas de saúde, assistência social, pedagogia e psicologia, para apoiar o trabalho dos (as) professores da educação básica com os (as) alunos (as) com deficiência, transtornos globais do desenvolvimento e altas habilidades ou superdotação;

4.6) manter e ampliar programas suplementares que promovam a acessibilidade nas instituições públicas, para garantir o acesso e a permanência dos (as) alunos (as) com deficiência por meio da adequação arquitetônica, da oferta de transporte acessível e da disponibilização de material didático próprio e de recursos de tecnologia assistiva, assegurando, ainda, no contexto escolar, em todas as etapas, níveis e modalidades de ensino, a identificação dos (as) alunos (as) com altas habilidades ou superdotação;

4.7) garantir a oferta de educação bilíngue, em Língua Brasileira de Sinais - LIBRAS como primeira língua e na modalidade escrita da Língua Portuguesa como segunda língua, aos (às) alunos (as) surdos e com deficiência auditiva de 0 (zero) a 17 (dezessete) anos, em escolas e classes bilíngues e em escolas inclusivas, nos termos do art. 22 do Decreto no 5.626, de 22 de dezembro de 2005, e dos arts. 24 e 30 da
Convenção sobre os Direitos das Pessoas com Deficiência, bem como a adoção do Sistema Braille de leitura para cegos e surdos-cegos;

4.8) garantir a oferta de educação inclusiva, vedada a exclusão do ensino regular sob alegação de deficiência e promovida a articulação pedagógica entre o ensino regular e o atendimento educacional especializado;

4.9) fortalecer o acompanhamento e o monitoramento do acesso à escola e ao atendimento educacional especializado, bem como da permanência e do desenvolvimento escolar dos (as) alunos (as) com deficiência, transtornos globais do desenvolvimento e altas habilidades ou superdotação beneficiários (as) de programas de transferência de renda, juntamente com o combate às situações de discriminação, preconceito e violência, com vistas ao estabelecimento de condições adequadas para o sucesso educacional, em colaboração com as famílias e com os órgãos públicos de assistência social, saúde e proteção à infância, à adolescência e à juventude;

4.10) fomentar pesquisas voltadas para o desenvolvimento de metodologias, materiais didáticos, equipamentos e recursos de tecnologia assistiva, com vistas à promoção do ensino e da aprendizagem, bem como das condições de acessibilidade dos (as) estudantes com deficiência, transtornos globais do desenvolvimento e altas habilidades ou superdotação;

4.11) promover o desenvolvimento de pesquisas interdisciplinares para subsidiar a formulação de políticas públicas intersetoriais que atendam as especificidades educacionais de estudantes com deficiência, transtornos globais do desenvolvimento e altas habilidades ou superdotação que requeiram medidas de atendimento especializado;

4.12) promover a articulação intersetorial entre órgãos e políticas públicas de saúde, assistência social e direitos humanos, em parceria com as famílias, com o fim de desenvolver modelos de atendimento voltados à 
continuidade do atendimento escolar, na educação de jovens e adultos, das pessoas com deficiência e transtornos globais do desenvolvimento com idade superior à faixa etária de escolarização obrigatória, de forma a assegurar a atenção integral ao longo da vida;

4.13) apoiar a ampliação das equipes de profissionais da educação para atender à demanda do processo de escolarização dos (das) estudantes com deficiência, transtornos globais do desenvolvimento e altas habilidades ou superdotação, garantindo a oferta de professores (as) do atendimento educacional especializado, profissionais de apoio ou auxiliares, tradutores (as) e intérpretes de Libras, guias-intérpretes para surdos-cegos, professores de Libras, prioritariamente surdos, e professores bilíngues;

4.14) definir, no segundo ano de vigência deste $\mathrm{PNE}$, indicadores de qualidade e política de avaliação e supervisão para o funcionamento de instituições públicas e privadas que prestam atendimento a alunos com deficiência, transtornos globais do desenvolvimento e altas habilidades ou superdotação;

4.15) promover, por iniciativa do Ministério da Educação, nos órgãos de pesquisa, demografia e estatística competentes, a obtenção de informação detalhada sobre o perfil das pessoas com deficiência, transtornos globais do desenvolvimento e altas habilidades ou superdotação de 0 (zero) a 17 (dezessete) anos;

4.16) incentivar a inclusão nos cursos de licenciatura e nos demais cursos de formação para profissionais da educação, inclusive em nível de pósgraduação, observado o disposto no caput do art. 207 da Constituição Federal, dos referenciais teóricos, das teorias de aprendizagem e dos processos de ensino-aprendizagem relacionados ao atendimento educacional de alunos com deficiência, transtornos globais do desenvolvimento e altas habilidades ou superdotação;
4.17) promover parcerias com instituições comunitárias, confessionais ou filantrópicas sem fins lucrativos, conveniadas com o poder público, visando a ampliar as condições de apoio ao atendimento escolar integral das pessoas com deficiência, transtornos globais do desenvolvimento e altas habilidades ou superdotação matriculadas nas redes públicas de ensino;

4.18) promover parcerias com instituições comunitárias, confessionais ou filantrópicas sem fins lucrativos, conveniadas com o poder público, visando a ampliar a oferta de formação continuada e a produção de material didático acessível, assim como os serviços de acessibilidade necessários ao pleno acesso, participação e aprendizagem dos estudantes com deficiência, transtornos globais do desenvolvimento e altas habilidades ou superdotação matriculados na rede pública de ensino;

4.19) promover parcerias com instituições comunitárias, confessionais ou filantrópicas sem fins lucrativos, conveniadas com o poder público, a fim de favorecer a participação das famílias e da sociedade na construção do sistema educacional inclusivo.” (PNE, 2014):

Segundo as informações acima transcritas do site do MEC, a educação inclusiva deve abarcar todos os níveis de escolaridade (Educação infantil - Ensino superior) e dispõe de Atendimento Educacional Especializado (AEE) para capacitar os professores e os alunos quanto à utilização da metodologia.

Vale ressaltar que a escola especial não caiu em extinção. É nela que os alunos dispõem do AEE como complemento e apoio ao ensino regular, sempre que preciso, sem que seja uma troca à escola regular. Assim, a educação especial deixa 
de ser substituta e passa a ser um modo complementar, sem deixar de existir.

- Alguns recursos são primordiais para o desenvolvimento do ambiente educacional dos quais os alunos podem dispor, de acordo com as suas respectivas deficiências:

- Deficiência visual e auditiva: linguagens e códigos específicos de comunicação e sinalização (ex: Braille, LIBRAS).

- Deficiência intelectual: mediação para desenvolver estratégias de pensamento (ex.: comunicação alternativa).

- Deficiência física: adequação do material escolar e do ambiente físico (ex.: cadeiras, tecnologia assistiva).

- Transtorno do espectro autista (autismo): abordagens diferentes para adequação e orientação do comportamento (ex.: comunicação alternativa).

- Altas habilidades: aumento dos recursos educacionais e/ou aceleração de conteúdo.

O público-alvo do Plano Nacional de Educação (PNE) quanto à educação inclusiva, são os alunos com deficiência (intelectual, física, auditiva, visual e múltipla), com transtorno do espectro autista e com altas habilidades (superdotados).
No que diz respeito às normativas escritas da inclusão no setor da educação, o discurso elaborado é positivo, motivacional e esperançoso, contudo, a prática há uma falha no processo inclusivo de qualidade. $\mathrm{O}$ desenrolar dessa realidade, na maioria das cidades, está engatinhando, no início, e assim mesmo há resistência para colocá-lo na dinâmica escolar, pois é mais cômodo negar a realidade ao invés de aceitar responsabilidades para a escola incluir todos os alunos.

\section{Inclusão educacional e deficiência auditiva}

Sabemos que ainda é polêmico falar sobre inclusão educacional nos mais diferentes públicos, incluindo, principalmente, o familiar e o escolar, lócus das diferenças. Embora nas políticas educacionais, na Lei de Diretrizes e Base da Educação Nacional (LDB) 9.394/96, Capítulo V, art. 60, parágrafo único, do Governo Federal, estabeleça "como alternativa preferencial, a ampliação do atendimento aos educandos com deficiência, transtornos globais do desenvolvimento e altas habilidades ou superdotação na própria rede pública regular de ensino" (BRASIL, 2017, p. 41), a segregação é uma realidade dura de lidar, pois, além de existir fora de casa, ela habita também o ambiente familiar por medo do desconhecido. São pais e cuidadores que 
evitam levar a criança ao ambiente escolar regular com receio de que elas sofram algum preconceito ou até descuido e venha a se machucar física ou emocionalmente. Concomitantemente, há escolas que ignoram a inserção de alunos com deficiência por falta de verba para atender às requisições impostas à realidade de cada um ou por falta de preparo físico e profissional.

Ainda na LDB, no 9.394/96 (BRASIL, 1996), no Capítulo III, art. 4, inciso III, afirma ser dever do Estado garantir o "atendimento educacional especializado gratuito aos educandos com necessidades especiais, preferencialmente na rede regular de ensino". De modo inclusivo, o capítulo 5 da Lei supracitada fala dos aspectos referentes à Educação Especial

Inclusive, o Capítulo 5 da LDB 9.394/96 trata somente de aspectos referentes à educação especial na rede regular. A saber:

“Art. 58. Entende-se por educação especial, para os efeitos desta Lei, a modalidade de educação escolar oferecida preferencialmente na rede regular de ensino, para educandos com deficiência, transtornos globais do desenvolvimento e altas habilidades ou superdotação.

§ 1o Haverá, quando necessário, serviços de apoio especializado, na escola regular, para atender às peculiaridades da clientela de educação especial.

§ $20 \mathrm{O}$ atendimento educacional será feito em classes, escolas ou serviços especializados, sempre que, em função das condições específicas dos alunos, não for possível a sua integração nas classes comuns de ensino regular.

§ 3o A oferta de educação especial, dever constitucional do Estado, tem início na faixa etária de zero a seis anos, durante a educação infantil.

Art. 59. Os sistemas de ensino assegurarão aos educandos com deficiência, transtornos globais do desenvolvimento e altas habilidades ou superdotação:

I - currículos, métodos, técnicas, recursos educativos e organização específicos, para atender às suas necessidades;

II - terminalidade específica para aqueles que não puderem atingir o nível exigido para a conclusão do ensino fundamental, em virtude de suas deficiências, e aceleração para concluir em menor tempo o programa escolar para os superdotados;

III - professores com especialização adequada em nível médio ou superior, para atendimento especializado, bem como professores do ensino regular capacitados para a integração desses educandos nas classes comuns;

IV - educação especial para o trabalho, visando a sua efetiva integração na vida em sociedade, inclusive condições adequadas para os que não revelarem capacidade de inserção no trabalho competitivo, mediante articulação com os órgãos oficiais afins, bem como para aqueles que apresentam uma habilidade superior nas áreas artística, intelectual ou psicomotora;

$\mathrm{V}$ - acesso igualitário aos benefícios dos programas sociais suplementares disponíveis para o respectivo nível do ensino regular.

Art. 59-A. O poder público deverá instituir cadastro nacional de alunos com altas habilidades ou superdotação matriculados na educação básica e na educação superior, a fím de fomentar a execução de políticas públicas destinadas ao desenvolvimento pleno das potencialidades desse alunado. 
Parágrafo único. A identificação precoce de alunos com altas habilidades ou superdotação, os critérios e procedimentos para inclusão no cadastro referido no caput deste artigo, as entidades responsáveis pelo cadastramento, os mecanismos de acesso aos dados do cadastro e as políticas de desenvolvimento das potencialidades do alunado de que trata o caput serão definidos em regulamento.

Art. 60. Os órgãos normativos dos sistemas de ensino estabelecerão critérios de caracterização das instituições privadas sem fins lucrativos, especializadas e com atuação exclusiva em educação especial, para fins de apoio técnico e financeiro pelo Poder Público.

Parágrafo único. O poder público adotará, como alternativa preferencial, a ampliação do atendimento aos educandos com deficiência, transtornos globais do desenvolvimento e altas habilidades ou superdotação na própria rede pública regular de ensino, independentemente do apoio às instituições previstas neste artigo." (BRASIL, 2017, pp. 39-41).

Entre os pontos especificados do art. 58 , o $§ 1^{\circ}$ (BRASIL, 2017) deixa claro às escolas regulares que, quando necessário, tem que existir suporte especializado de apoio para atender às necessidades de cada aluno especial. Exemplificando: se em uma sala regular um aluno surdo, que necessita de um professor/acompanhador que conheça ou domine a Língua Brasileira de Sinais (LIBRAS), a escola deve fornecer esse profissional capacitado para auxiliá-lo nas disciplinas.

Atualmente é comum ver alunos com necessidades especiais frequentando escolas de ensino regular da rede pública, mas, ainda mais, na rede privada, tornandose participantes da grande rede de inclusão educacional, importante para que, independente da deficiência e do nível de comprometimento, na classe regular os alunos possam ter um desenvolvimento intelectual, físico e social.

Mostra-se um avanço significativo, pois jovens viviam excluídos do meio social, não tendo oportunidade de estimular a consciência e o corpo, tendo ofuscado o direito de desenvolvimento psicomotor, tendo, ainda, o direito de convívio negligenciado. Vivia à margem da sociedade, mas, em alguns casos, sufocado com a superproteção dos seus pais ou cuidadores; ainda pior, quando eram rejeitados ou maltratados por não serem compreendidos e cobrados por coisas que, diferentes de outros, não tinha condições de fazer.

Contudo, para que a inclusão escolar de fato aconteça, os professores precisam estar preparados para lidar com qualquer tipo de situação. O art. 59, da LDB, inciso III (BRASIL, 2017), diz que os sistemas de ensino devem assegurar aos educandos com necessidades especiais "professores com especialização adequada em nível médio ou superior, para atendimento especializado, bem como professores do ensino regular capacitados para a integração desses educandos nas classes comuns" (p. 40). 
Porém, a realidade é outra, não é o que Silva e Retondo (2008) apud Bueno (1999), relatam ao verificar que:

\begin{abstract}
"de um lado, os professores do ensino regular não possuem preparo mínimo para trabalhar com crianças que apresentem deficiências evidentes e, por outro, grande parte dos professores do ensino especial tem muito pouco a contribuir com o trabalho pedagógico desenvolvido no ensino regular, na medida em que têm calcado e construído sua competência nas dificuldades específicas do alunado que atendem." (SILVA E RETONDO, 2008, p. 28 apud SOUZA, 2018, p. 7).
\end{abstract}

Torna-se urgente que os profissionais estejam qualificados e que, assim como para a inclusão na escola seja desde o início, desde o fundamental, então que para os profissionais a qualificação seja desde o início do curso para que recebam preparos de como lidar com os casos de crianças com necessidades especiais. Assim, estudantes em formação, e os já formados, estejam "atentos para propostas pedagógicas que auxiliem os docentes no melhoramento de suas concepções e fazeres escolares" (SILVEIRA E SOUZA, 2011, p. 37).

Os professores enfrentam dificuldades não só em transmitir para esses alunos as disciplinas específicas em suas áreas de formação, mas falta também o próprio conhecimento "para lidar com a língua brasileira de sinais (libras) e com a presença de intérpretes em suas aulas" (SILVEIRA E SOUZA, 2011, p. 38). Ainda mais quando se trata de professores da disciplina de Química, pois a dificuldade é maior para construir conhecimento e passar as informações para os alunos surdos10, porque a Química contém uma linguagem específica, que muitas vezes não tem como ser traduzida para LIBRAS.

O resultado é que mesmo estando em sala de aula, muitos alunos com necessidades especiais acabam sendo apartados ou excluídos, ocorre um distanciamento deles, que não conseguem dar continuidade aos estudos.

\section{Quem é o surdo?}

A inclusão escolar é uma evolução que busca aprimoramento conforme as necessidades do aluno surdo e a determinação de leis e diretrizes, e a escola é responsável por passar por um processo de readaptação estrutural e educacional para receber o aluno surdo e auxiliar no seu desenvolvimento escolar.

\footnotetext{
"A questão da inclusão não é algo que envolve apenas a surdez, mas se refere a uma reflexão mais ampla da sociedade, buscando formas de melhor se relacionar com sujeitos de outra cultura, que falam outra língua, que professam outra fé religiosa, entre outros. Trata-se de um tema muito debatido atualmente e que busca refletir sobre formas adequadas de convivência, ampliando os conhecimentos sobre a realidade
} 
cultural do outro, sem restrição ou exigência de adaptação às regras do grupo majoritário. Trata-se de uma discussão sobre os modos de convivência dos grupos humanos nas suas diferenças que não é simples e que não se mostra ainda bem resolvida, seja na esfera política, religiosa, econômica ou educacional." (CAD. CEDES V.26 N.69 CAMPINAS MAIO/AGO. 2006 apud MARILENE E MEYER, 2016, p. 8).

É primordial sabermos sobre o aluno surdo para melhor desempenho de trabalho com ele. Segundo Marilene e Meyer (2016), “o aluno surdo é aquele sujeito cujo sentido auditivo apresenta perca considerada dentro da escala de normalidade, sendo classificada em grau de perda leve, moderada, severa e profunda" (p. 28). A surdez está ligada a uma questão linguística, cultural e biológica, no entanto, a pessoa surda se identificam e se caracterizam muito mais por uma questão indenitária de uso da língua de sinais do que propriamente por uma questão de perdas auditivas. Para Luz: “A surdez é um importante
componente do conjunto corpóreo a
partir do qual as pessoas que vivem
essa condição buscam realização
psicossomática como seres únicos, se
singularizam, podem adquirir uma
língua plena e, comumente - no

\section{CONCLUSÃO}

A educação inclusiva no Brasil está caminhando a passos lentos, sabemos a importância do investimento de recursos financeiros e legislativo do governo. Contudo, a partir do que foi exposto, vemos a necessidade de um contínuo

\begin{abstract}
sentido relacional -, são comprometidas/tratadas pelos que estão a sua volta - e dos quais dependem. Os surdos são, antes de tudo, uma minoria sensorial. Ser minoria linguística - como legitimamente muitos deles lutam para ser reconhecidos - deriva do fato de serem significativamente diferentes do ponto de vista sensorial, com consequências não só para a questão de um idioma mais experienciável, mas também para seu modo de ser no mundo." (LUZ, 2013, p 18).
\end{abstract}

Tendo conhecimento sobre quem é o aluno surdo, diminui a dificuldade de trabalhar com ele, é por isso que:

"É necessário conhecer quem são
esses sujeitos, quais suas
especificidades, pois há algumas
pessoas surdas que falam e fazem
leitura labial muito bem outras
comunicam - se através de mímicas,
outras por língua de sinais e algumas
usam sinais e oralização em situações
diferentes - são os surdos bilíngües.
Por trás de cada um desses contextos,
há um histórico sociocultural que
precisa ser levantado para que se tenha
a clareza do ponto de partida e do
percurso educacional adequado a
característica desses sujeitos."
(BRASIL, 2014, p. 29). O surdo é privado da exposição pela falta de audição e, devido a isso, o desenvolvimento fica em desvantagem. Sua capacidade de aprender é impraticável bem na partida.

aprimoramento de publicações de estudos científicos sobre a inclusão de alunos especiais nas escolas, e, por parte dos professores, uma atualização formativa continuada, afim de sanar os pontos decadentes da forma de lidar com alunos com necessidades auditivas. 
Para aprimoramento do processo de integração dos alunos surdos com os profissionais competentes de uma escola, é importante a inclusão da LIBRAS para que o aluno se sinta parte da sala, de um grupo, construindo sua identidade a partir da relação com os outros, participando ativamente das atividades propostas, isso tudo para que ele seja parte do convívio escolar.

Caso contrário, a interação do aluno surdo será comprometida ou limitada quando mantém contato apenas com o intérprete, onde poderia interagir com mais pessoas quando a educação de LIBRAS, como meio de comunicação, passa ser vivida pelos outros alunos na mais nova série escolar aos funcionários da escola.

Uma das principais ferramentas da espécie humana é a comunicação e "quando é verdadeira, quando nasce da necessidade de dizer, a voz humana não encontra quem a detalha. Se lhe negam a boca, ela fala

\section{REFERÊNCIAS}

ÁVILA, C. C. Contribuições do pacto nacional pela alfabetização na idade certa na formação de professores para atuar na perspectiva inclusiva. Tese [Doutorado em Educação], UFSM, Centro de Educação, Santa Maria - RS, 2018, 123 p. Disponível em:

<https://repositorio.ufsm.br/handle/1/1568 6> Acesso em: 27/Dez. 2019. pelas mãos, ou pelos olhos, ou pelos poros, ou por onde for. Porque todos, todos, temos algo a dizer aos outros, alguma coisa, alguma palavra que merece ser celebrada ou perdoada" (GALEANO, 2002, p. 23). Temos a necessidade de nos comunicar de alguma maneira, independente da forma com que o contato será feito.

Mas, para que haja inclusão com responsabilidade e comprometimento nas escolas, com os alunos com necessidades especiais ou não, professores, funcionários, respectivos intérpretes, que existem outras ações educacionais necessárias para práticas inclusivas, não apenas no ambiente escolar, mas em todos os lugares onde há presença de surdos. Fazendo valer o que se compromete à política pública, cada um fazendo o que lhe compete, num contexto legal e moral, com o envolvimento de todos, só assim podemos dizer que a educação inclusiva está acontecendo.

BOMFIM, D. A. O processo de alfabetização de surdos nos anos iniciais do ensino fundamental: uma análise sob a perspectiva de professores. Dissertação [Mestrado em Educação, Cultura e Sociedade], UFVJM, Programa de PósGraduação Interdisciplinar em Ciências Humanas, Diamantina - MG, 2017, 188 p. Disponível em: <https://repositorio.ufsc.br/handle/1234567 89/187709> Acesso em: 28/Dez. 2019. 
BRASIL. Secretaria de Educação Básica. Diretoria de Apoio à Gestão Educacional. Caderno de educação especial: a alfabetização de crianças com deficiência: uma proposta inclusiva/ Ministério da Educação, Secretaria de Educação Básica, Diretoria de Apoio à Gestão Educacional. - Brasília: MEC, SEB, 2014. 48 p.

BRASIL. Senado Federal. Lei de Diretrizes e Bases da Educação Nacional. Edição atualizada em março de 2017, pp. 39-41. Disponível em: <https://www2.senado.leg.br/bdsf/bitstrea m/handle/id/529732/lei_de_diretrizes_e_ba ses_1ed.pdf $>$ Acesso em:

s/BoasPraticas/INCLMUDANCAOLHAR COMUNESCOLARCONSTRESCOLAM ELHORINCLUSIVA.pdf $>$ Acesso em: 28/Dez. 2019.

CAETANO, E. R. S. As concepções dos professores a respeito da inclusão dos alunos com necessidades educacionais especiais: uma discussão em grupo.

Dissertação [Mestrado em Profissional em Educação]. UNIPAMPA, Programa de Pós-Graduação em Educação, Jaguarão, 2019, 90 p. Disponível em: <http://dspace.unipampa.edu.br:8080/jspui /handle/riu/4573> Acesso em: 27/Dez. 2019.

CALHEIROS, D. S. Rede de apoio à escolarização inclusiva na educação básica: dos limites às possibilidades. Tese [Doutorado em Educação Especial]. UFSCAR, Centro de Educação e Ciências Humanas, São Paulo - SP, 2019, 205 p. Disponível em: <https://repositorio.ufscar.br/handle/ufscar/ 11292 >. Acesso em: 27/Dez. 2019.

DILL, J. K. Educação especial e educação integral: um estudo de caso sobre as interfaces em uma escola pública.

Dissertação [Mestrado em Educação em Ciências], UFRGS, Instituto de Ciências Básicas da Saúde, Porto Alegre, 2019, 106 p. Disponível em: <https://lume.ufrgs.br/handle/10183/19460 9>_Acesso em: 27/Dez. 2019.

FLORES, A. S. Gestão escolar e educação inclusiva: articulação entre o atendimento educacional especializado e o ensino regular. Dissertação [Mestrado em Ensino e Processos Formativos], UNESP, Instituto de Biociências, Letras e Ciências Exatas, São José do Rio Preto, 2018, 212 p. Disponível em: <https://repositorio.unesp.br/handle/11449/ 157289> Acesso em: 28/Dez. 2019.

FRANZOI, E. B. S. Interações da criança surda em escola comum. Dissertação [Mestrado em Educação], UCS, Programa de Pós-Graduação, Caxias do Sul, 2016, 99 p. Disponível em:

<https://repositorio.ucs.br/handle/11338/18 40> Acesso em: 28/Dez. 2019.

GALEANO, E. O livro dos abraços. Porto Alegre: L\&PM Editores, 2002.

HENCKLEIN, F. A. A interação social dentro de uma escola com perspectivas inclusivas: análise do ensino de Ciências para alunos surdos. Tese [Doutorado em Educação para a Ciência], UNESP, Faculdade de Ciências, Bauru, 2016, 250 p. Disponível em: <https://repositorio.unesp.br/handle/11449/ 190779> Acesso em: 28/Dez. 2019.

JESUS, C. K. A inclusão e escolarização dos alunos com deficiência auditiva e surdez no ensino fundamental em Brasilândia/MS: desafios, avanços e perspectivas. Dissertação [Mestrado em Educação], UEMS, Programa de PósGraduação em Educação, Paranaíba - MS, 2016, 119 p. Disponível em: <https://repositorio.ufsc.br/handle/1234567 89/190834> Acesso em: 28/Dez. 2019.

KIKUICHI, V. Z. F. Compondo sentidos sobre a inclusão do aluno surdo: as percepções dos sujeitos envolvidos no processo. Dissertação [Mestrado em 
Educação], UFTM, Programa de PósGraduação em Educação, Uberaba, 2018, 184 p. Disponível em:

<https://repositorio.ufsc.br/handle/1234567 89/191551> Acesso em: 27/Dez. 2019.

KONKEL, E. N.; ANDRADE, C.; KOSVOSKI, D. M. C. As dificuldades no processo de inclusão educacional no ensino regular: a visão dos professores do ensino fundamental. EDUCERE,

Formação de Professores, Complexidade e Trabalho Docente - IX Encontro Nacional sobre Atendimento Escolar Hospitalar, 2015, 15 p. Disponível em:

<https://educere.bruc.com.br/arquivo/pdf2 015/19144_8387.pdf> Acesso em: 28/Dez. 2019.

LOURENÇO, A. A. A. Políticas para Educação Inclusiva no Município de Campinas: o que dizem as legislações nacionais e municipais. Dissertação [Mestrado em Política e Gestão Educacional]. UNESP, Faculdade de Ciências Humanas e Sociais, Franca - SP, 2019, 76 p. Disponível em:

<https://repositorio.unesp.br/handle/11449/ 181368> Acesso em: 27/Dez. 2019.

LUZ, R. D. Os surdos. In: Cenas surdas: os surdos terão lugar no coração do mundo? 1 ed. São Paulo: Parábola, 2013, p. 18.

MACHADO, J. L. N. Tenho um aluno surdo: aprendi o que fazer! Dissertação [Mestrado em Ensino de Ciências], UNB, Programa de Pós-Graduação em Ensino de Ciências, Brasília - DF, 2017, 149 p. Disponível em:

<https://repositorio.unb.br/handle/10482/2 4621> Acesso em: 28/Dez. 2019.

MANTOAN, M. T. E.; PIETRO, R. G.; ARANTES, V. A. Inclusão Escolar: pontos e contrapontos. São Paulo: Summus, p. 103, 2006.
MARCELINO, R. I. F. Formação continuada do gestor escolar: instrumento facilitador no processo de inclusão de alunos com deficiência nas escolas estaduais de Uberaba. Dissertação [Mestrado em Profissional em Gestão e Avaliação da Educação Pública]. UFJF, Centro de Políticas Públicas e Avaliação da Educação, Juiz de Fora, 2019, 113 p. Disponível em: $<$ https://repositorio.ufjf.br/jspui/handle/ufjf /11447> Acesso em: 27/Dez. 2019.

MARILENE, D.; MEYER, V. A. A importância da LIBRAS para inclusão escolar do surdo. Cadernos PDE [Versão Online], volume 1, 2016, 25 p. Disponível em:

$<$ http://www.diaadiaeducacao.pr.gov.br/po rtals/cadernospde/pdebusca/producoes_pde /2016/2016_artigo_edespecial_unicentro_ marilenedomanovski.pdf > Acesso em: 27/Nov. 2019.

MARTINS, C. A. F. A inclusão de crianças com deficiência na educação infantil: políticas públicas na visão dos professores. Dissertação [Mestrado em Planejamento e Análise de Políticas Públicas], UNESP, Faculdade de Ciências Humanas e Sociais, Franca - SP, 2018, 152 p. Disponível em:

<https://repositorio.unesp.br/handle/11449/ 157210> Acesso em: 28/Dez. 2019.

MATOS, M. A. P. Biopolítica e educação: desafios da inclusão escolar das pessoas com deficiência no neoliberalismo.

Dissertação [Mestrado em Filosofia da Educação]. UNESP, Faculdade de Filosofia e Ciências, Marília, 2019, 81 p. Disponível em:

<https://repositorio.unesp.br/handle/11449/ 182083> Acesso em: 27/Dez. 2019.

MIRANDA, F. D. Educação inclusiva em um município do interior goiano: análise de um percurso. Dissertação [Mestrado em Educação], UFG, Programa de PósGraduação em Educação, Jataí - GO, 
2019, 125 p. Disponível em:

<http://repositorio.bc.ufg.br/tede/handle/te de/9395> Acesso em: 28/Dez. 2019.

MORÁS, N. A. B. A cultura da escola inclusiva na perspectiva dos alunos surdos. Dissertação [Mestrado em Ensino], UNIOESTE, Programa de Pós-Graduação em Ensino, Foz do Iguaçu, 2018, 126 p. Disponível em:

<http://tede.unioeste.br/handle/tede/3533> Acesso em: 28/Dez. 2019.

NASCIMENTO, S. S. Educação especial e inclusão escolar na educação infantil e anos iniciais do ensino fundamental. Dissertação [Mestrado em Educação], UFG, Unidade Acadêmica Especial de Educação, Catalão - GO, 2019, 196 p. Disponível em:

<http://repositorio.bc.ufg.br/tede/handle/te de/9701> Acesso em: 27/Dez. 2019.

OLIVEIRA, L. A. Pedagogia na UFS: o lugar da educação inclusiva numa realidade excludente. Dissertação

[Mestrado em Educação], UFS, Programa de Pós-Graduação em Educação, São Cristóvão - SE, 2019, 157 p. Disponível em:

<https://ri.ufs.br/jspui/handle/riufs/11403> Acesso em:

PAPA, F.; VIÉGAS, S. A. G.; ZAMOR, A. V. et. al. Inclusão: uma mudança no olhar da comunidade escolar para a construção de uma escola melhor inclusiva. Boas Práticas na perspectiva da Educação Especial Inclusiva, volume 1, 2015, 9 p. Disponível em:

<http://cape.edunet.sp.gov.br/cape_arquivo s/BoasPraticas/INCLMUDANCAOLHAR COMUNESCOLARCONSTRESCOLAM ELHORINCLUSIVA.pdf> Acesso em: 28/Dez. 2019.

PERALES, H. L. Práticas pedagógicas do professor de história de ensino médio em turma regular com a presença de aluno surdo. Dissertação [Mestrado em
Educação], UFG, Programa de PósGraduação em Educação, Natal - RN, 2018, 171 p. Disponível em: <https://repositorio.ufrn.br/jspui/handle/12 3456789/25803> Acesso em: 28/Dez. 2019.

PIO, D. N. A. Currículo e diferença na educação especial em uma perspectiva inclusiva. Dissertação [Mestrado em Educação], UFG, Jataí - GO, 2018, 110 p. Disponível em:

$<$ http://repositorio.bc.ufg.br/tede/handle/te de/8256> Acesso em: 27/Dez. 2019.

RAMOS, D. M. Educação de surdos: estudo bibliométrico de teses e dissertações (2010-2014). Tese [Doutorado em Educação Especial], UFSCAR, Centro de Educação e Ciências Humanas, São Carlos, 2017, 214 p. Disponível em: <https://repositorio.ufscar.br/handle/ufscar/ 8830> Acesso em: 28/Dez. 2019.

REIS, E. H. M. O surdo na perspectiva inclusiva: acesso, permanência e êxito no ensino (?). Tese [Doutorado em Serviço Social], UNESP, Faculdade de Ciências Humanas e Sociais, Franca, 2019, 159 p. Disponível em: <https://repositorio.unesp.br/handle/11449/ 182306> Acesso em: 28/Dez. 2019.

RUZZA, M. L. F. A inclusão educacional do sujeito surdo: direito garantido ou reprimido?. Dissertação [Mestrado em Educação], PUC-SP, São Paulo, 2016, 134 p. Disponível em: <https://tede2.pucsp.br/handle/handle/1884 1> Acesso em: 28/Dez. 2019.

SANTOS, M. C. C. Investigação matemática em sala de aula: uma proposta para a inclusão do aluno surdo no ensino regular. Dissertação [Mestrado em Educação para Ciências e Matemática], IFG, Instituto Federal de Educação, Ciência e Tecnologia, Jataí, 2015, 154 p. Disponível em: 
<https://repositorio.ufsc.br/handle/1234567 89/191000> Acesso em: 28/Dez. 2019.

SANTOS, P. J. A. Ensino de História para alunos surdos em classes inclusivas: práticas e propostas. Dissertação [Mestrado em Ensino de História], UFRJ, Instituto de História, Rio de Janeiro, 2018, 206 p. Disponível em:

<https://repositorio.ufsc.br/handle/1234567 89/190874> Acesso em: 28/Dez. 2019.

SENA, F. S. O letramento do aluno surdo na escola regular: perspectivas e desafios. Dissertação [Mestrado em Linguística e Ensino], UFPA, Centro de Ciências Humanas, Letras e Artes, João Pessoa PB, 2017, 146 p. Disponível em: <https://repositorio.ufsc.br/handle/1234567 89/190789> Acesso em: 28/Dez. 2019.

SILVA, A. Práticas pedagógicas na educação de surdos: análise crítica do discurso de professores da educação básica. Dissertação [Mestrado em Letras], UFS, Programa de Pós-Graduação em Letras, São Cristóvão - SE, 2017, 138 p. Disponível em:

<https://ri.ufs.br/jspui/handle/riufs/8202> Acesso em: 28/Dez. 2019.

SILVA, R. R. Formação de professores de matemática e o ensino de matemática para estudantes surdos: reflexões acerca da educação inclusiva. Dissertação [Mestrado em Educação em Ciências e Matemática], UFPE, Programa de Pós-Graduação em Educação em Ciências e Matemática, Caruaru, 2019, 74 p. Disponível em: <https://repositorio.ufpe.br/handle/123456 789/34497> Acesso em: 28/Dez. 2019.
SIQUEIRA, A. S. N. Surdez, linguagem e educação: quem ouve o sujeito surdo?. Dissertação [Mestrado em Letras], UFAM, Instituto de Ciências Humanas e Letras, Manaus, 2015, 147 p. Disponível em: $<$ https://tede.ufam.edu.br/handle/tede/4821 > Acesso em: 28/Dez. 2019.

SOUZA, M. A. A formação dos professores na educação inclusiva: compreender, mudar, incluir. $4^{\circ}$ Encontro Estadual da Associação Nacional pela Formação de Professores Seção Sergipe. 2018, 10 p. Disponível em: $<$ https://eventos.set.edu.br/index.php/enfop e/article/download/9134/3855> Acesso em: 28/Dez. 2019.

TEIXEIRA, A. M. Inclusão escolar na perspectiva docente: a realidade do atendimento educacional especializado nas escolas públicas municipais de Uruguaiana/RS. Tese [Doutorado em Educação em Ciências: Química da Vida e Saúde]. UNIPAMPA, Uruguaiana - RS, 2019, 107 p. Disponível em:

$<$ http://dspace.unipampa.edu.br:8080/jspui /handle/riu/4492> Acesso em: 27/Dez. 2019.

ZIESMANN, C. I. Práticas pedagógicas em sala de aula com surdos: implicações nos processos de ensino e de aprendizagem. Dissertação [Mestrado em Educação nas Ciências], UNIJUÍ, Curso de Pós-Graduação Stricto Sensu, Ijuí - RS, 2015, 125 p. Disponível em: <http://bibliodigital.unijui.edu.br:8080/xml ui/handle/123456789/4986> Acesso em: 28/Dez. 2019. 